\title{
Comment on "Under-the-Flap Crosslinking and LASIK in Early Ectasia with Hyperopic Refractive Error"
}

\author{
Avi Wallerstein (D), ${ }^{1,2}$ Mathieu Gauvin, ${ }^{2}$ and Mark Cohen ${ }^{2,3}$ \\ ${ }^{1}$ Department of Ophthalmology, Faculty of Medicine, McGill University, Montreal, QC, Canada \\ ${ }^{2}$ LASIK MD, Montreal, QC, Canada \\ ${ }^{3}$ Department of Surgery, Faculty of Medicine and Health Sciences, University of Sherbrooke, Sherbrooke, QC, Canada \\ Correspondence should be addressed to Avi Wallerstein; awallerstein@lasikmd.com
}

Received 6 February 2019; Accepted 29 May 2019; Published 1 July 2019

Academic Editor: Suphi Taneri

Copyright (c) 2019 Avi Wallerstein et al. This is an open access article distributed under the Creative Commons Attribution License, which permits unrestricted use, distribution, and reproduction in any medium, provided the original work is properly cited.

We read with great interest the article by el-Khoury et al. "Under-the-Flap Crosslinking and LASIK in Early Ectasia with Hyperopic Refractive Error" [1]. It is encouraging to see clinical work with the goal of stabilizing the progression of early post-LASIK ectasia and improving visual outcomes. In their article, a combination of excimer laser ablation and corneal collagen crosslinking (CXL) was performed under an existing LASIK flap.

Sequential excimer laser ablation with CXL has been previously described for the management of cornea ectasia after LASIK [2-4]. The novelty of el-Khoury's article is applying this combination "under-flap" instead of performing a corneal surface treatment with epithelial removal.

While el-Khoury and colleagues included key references on CXL combined with excimer laser ablation in their article, we noted an important omission of the source reference that first introduced and described the "under-flap" approach to CXL in patients with early ectasia. The article "Under-flap stromal bed CXL for early post-LASIK ectasia: a novel treatment technique" was published in Clinical Ophthalmology in December 2016 [5]. This article is the first to describe and report on outcomes of performing CXL performed under a previous LASIK flap.

The unintentional omission of this reference might lead the readers to wrongfully believe that Dr. el-Khoury and colleagues were the first to describe an under-flap approach to CXL in the management of early post-LASIK ectasia. We would kindly ask Dr. el-Khoury to update his reference list so that the readers can be better informed of the origins of the under-flap method for CXL.

We would like to congratulate the authors for their contribution to the field.

\section{Conflicts of Interest}

The authors declare that there are no conflicts of interest and no financial interest in the subject matter or materials presented herein.

\section{References}

[1] S. el-Khoury, Y. Abdelmassih, M. Amro, E. Chelala, and E. Jarade, "Under-the-Flap crosslinking and LASIK in early ectasia with hyperopic refractive error," Journal of Ophthalmology, vol. 2018, Article ID 4342984, 10 pages, 2018.

[2] A. J. Kanellopoulos and P. S. Binder, "Management of corneal ectasia after LASIK with combined, same-day, topographyguided partial transepithelial PRK and collagen cross-linking: the athens protocol," Journal of Refractive Surgery, vol. 27, no. 5, pp. 323-331, 2011.

[3] G. D. Kymionis, D. M. Portaliou, V. F. Diakonis et al., "Management of post laser in situ keratomileusis ectasia with simultaneous topography guided photorefractive keratectomy and collagen cross-linking," Open Ophthalmology Journal, vol. 5, pp. 11-13, 2011.

[4] G. Tamayo, C. Castell, P. Vargas, E. Polania, and J. Tamayo, "High-resolution wavefront-guided surface ablation with 
corneal cross-linking in ectatic corneas: a pilot study," Clinical Ophthalmology, vol. 11, pp. 1777-1783, 2017.

[5] A. Wallerstein, E. Adiguzel, M. Gauvin, N. Mohammad-Shahi, and M. Cohen, "Under-flap stromal bed CXL for early postLASIK ectasia: a novel treatment technique," Clinical Ophthalmology, vol. 11, pp. 1-8, 2017. 


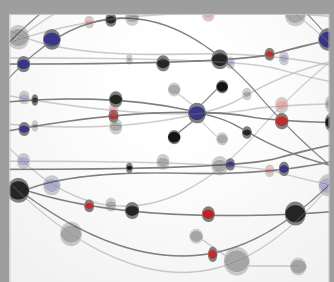

The Scientific World Journal
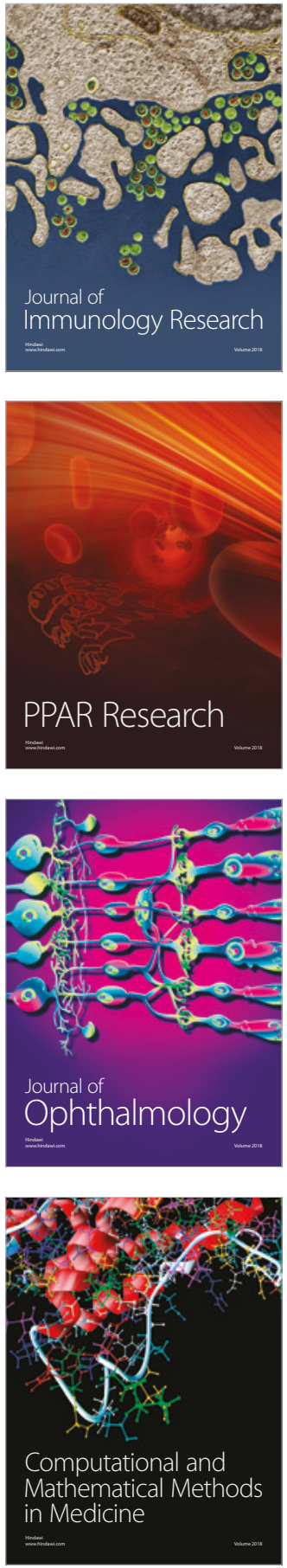

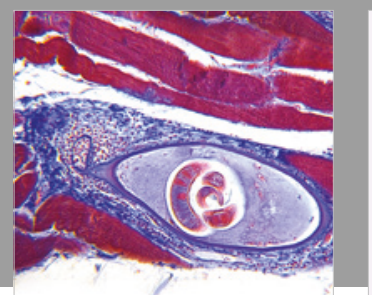

Gastroenterology Research and Practice

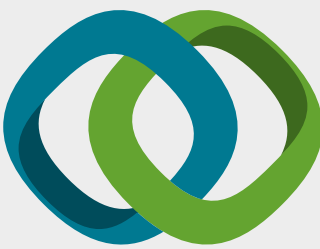

\section{Hindawi}

Submit your manuscripts at

www.hindawi.com
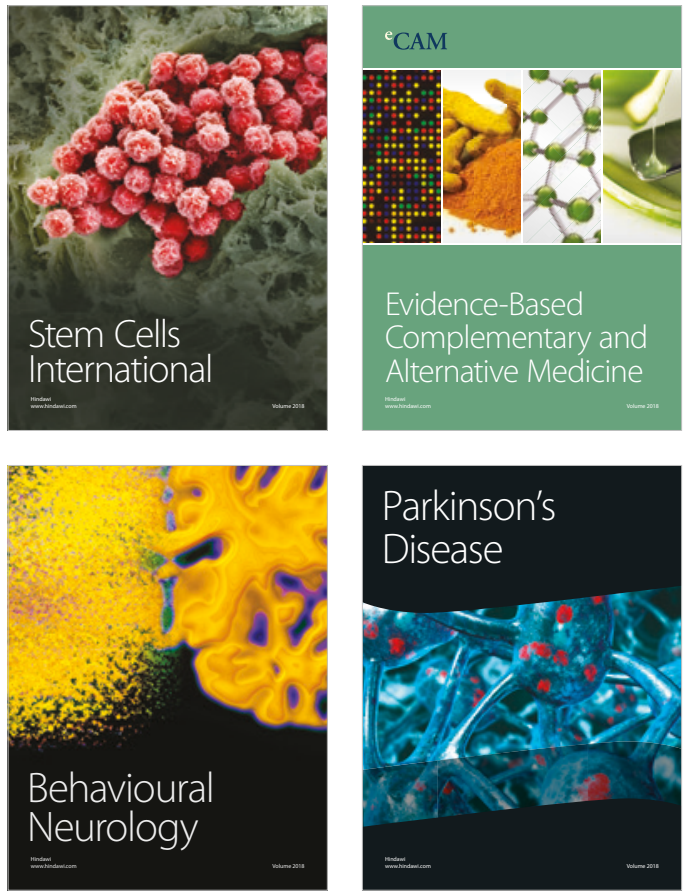

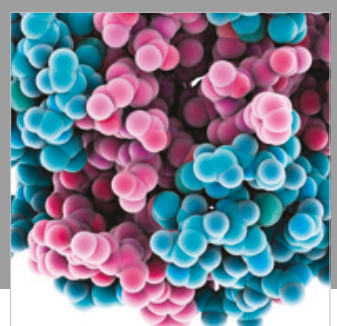

ournal of

Diabetes Research

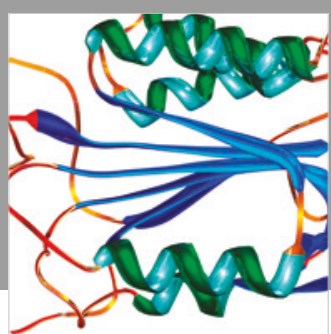

Disease Markers
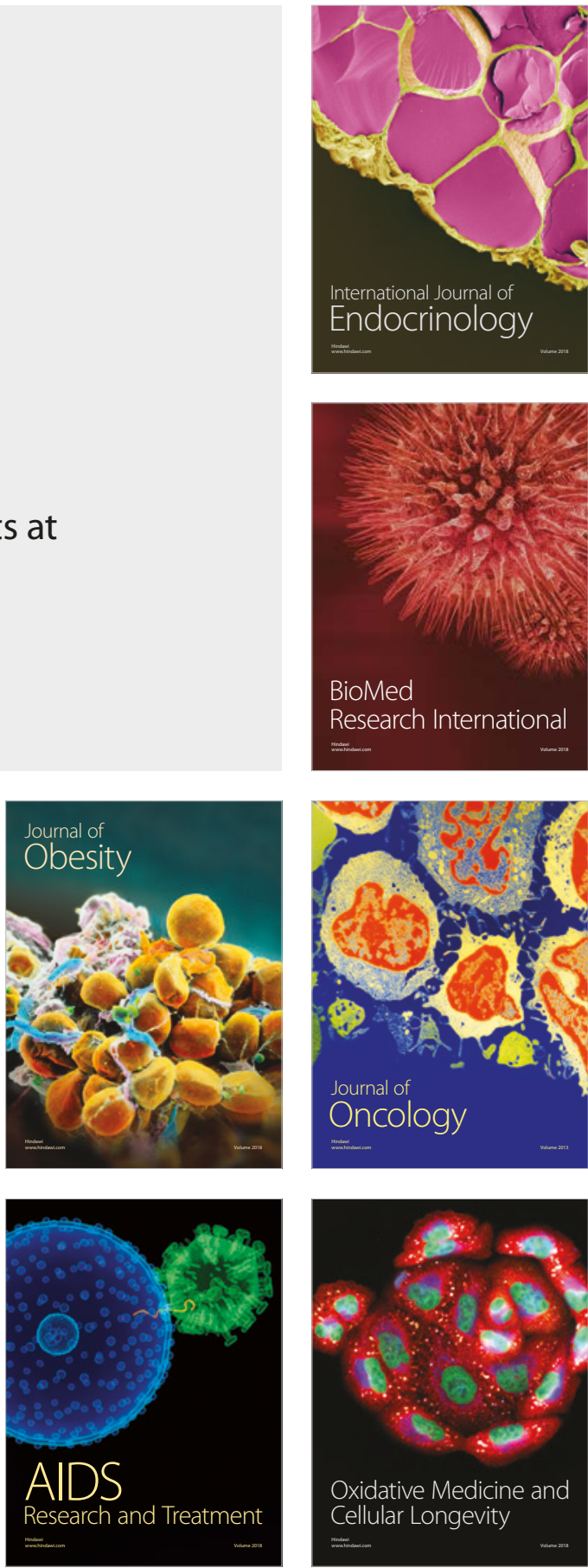